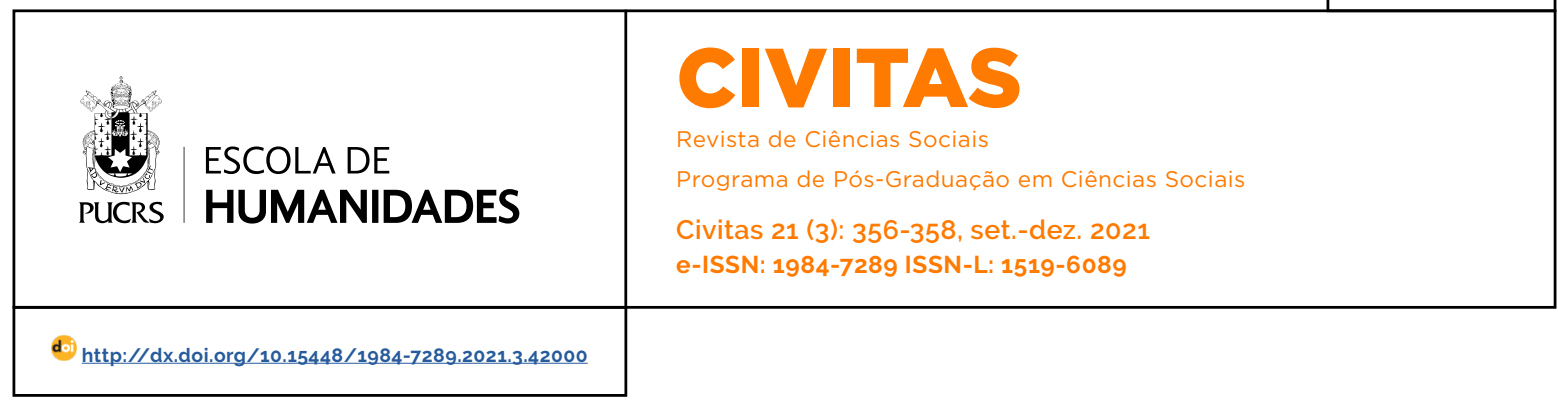

APRESENTAÇÃO/PRESENTATION

\title{
Interseccionalidades, direitos e políticas
}

Intersectionalities, rights and policies

\author{
Interseccionalidades, derechos y politicas
}

Miriam Steffen Vieira ${ }^{1}$

orcid.org/0000-0002-1973-1917 miriamsteffen@gmail.com

Eufémia Vicente Rocha ${ }^{2}$ orcid.org/0000-0001-7585-6661 eufemia.rocha@sapo.cv

Recebido em: 18 out. 2021. Aprovado em: 18 out. 2021 Publicado em: 8 nov. 2021.
Resumo: A noção de interseccionalidades emerge da experiência politica de feminismos negros e pauta as dinâmicas entrecruzadas que estão na base de desigualdades sociais como gênero, raça, sexualidades e classe. Dessa perspectiva, ela é tomada como uma possibilidade de produzir teoria e para se questionar analiticamente diversas experiências e contextos, gerando novas lições acerca dos processos de dominação. Além de uma ferramenta metodológica central; nas vivências e ações políticas, se apresenta como um campo aberto de resistências às narrativas e práticas hegemônicas ocidentais. Neste texto, apresentamos os artigos que compõem o Dossiê Interseccionalidades, direitos e políticas, com atenção à diversidade de abordagens e contribuições que permitem expandir a densidade dos fundamentos epistemológicos nas ciências sociais, como na práxis política.

Palavras-chave: Interseccionalidades. Feminismos Negros. Epistemologia Feminista.

Abstract: The notion of intersectionalities emerges from the political experience of black feminisms and guides the intersecting dynamics that underlie social inequalities such as gender, race, sexualities and class. Therefore, it is taken as a possibility to produce theory and to analytically question different experiences and contexts, generating new lessons about the processes of domination. In addition to being a central methodological tool, in the experiences and political actions, it presents itself as an open field of resistance to Western hegemonic narratives and practices. In this text, we present the articles that make up the Intersectionalities, rights and policies dossier. With attention to the diversity of approaches and contributions that allow expanding the density of epistemological foundations in social sciences, as in political praxis

Keywords: Intersectionalities. Black Feminisms. Feminist Epistemology.

Resumen: La noción de interseccionalidades surge de la experiencia política de los feminismos negros y guía las dinámicas de intersección que subyacen a las desigualdades sociales como el género, la raza, la sexualidad y la clase. Por lo tanto, ella se toma como una posibilidad de producir teoría y cuestionar analíticamente diferentes experiencias y contextos, generando nuevas lecciones sobre los procesos de dominación. Además de ser una herramienta metodológica central, en las experiencias y acciones políticas se presenta como un campo abierto de resistencia a las narrativas y prácticas hegemónicas occidentales. En este texto, presentamos los artículos que integran el Dossier Interseccionalidades, derechos y políticas, con atención a la diversidad de enfoques y aportes que permiten ampliar la densidad de fundamentos epistemológicos en las ciencias sociales, como en la praxis política.

Palabras clave: Interseccionalidades. Feminismos negros. Epistemología feminista. 
Neste texto, apresentamos os artigos que compõem o Dossiê Interseccionalidades, direitos e políticas, com atenção à diversidade de abordagens desenvolvidas e ao modo como permitem expandir os fundamentos epistemológicos das ciências sociais, assim como contribuem com a práxis política.

O texto que abre o dossiê, intitulado "Da interseccionalidade à encruzilhada: operações epistêmicas de mulheres negras nas universidades brasileiras" é fundamental para evidenciar esta dinâmica de mão dupla, ao produzir uma crítica ao modo como a conceituação de interseccionalidades, muitas vezes, acaba por ser capturada pela academia, neutralizando sua força política crítica. Winnie de Campos Bueno e José Carlos Gomes dos Anjos, a partir da relação de orientação em um programa de pós-graduação de ponta na área da sociologia brasileira, trazem reflexões sobre as estratégias de resistência desenvolvidas por pesquisadoras negras em relação à violência epistemológica operada pela ciência ocidental. Para a autora e o autor, "é possivel compreender a interseccionalidade como conhecimento de resistência e como projeto de justiça social", no sentido em que "os caminhos percorridos por mulheres negras para a sua subjetivação perpassam por estratégias interseccionais. A consciência das multiplicidades de experiências que existem nesse grupo exige um fazer político em que as particularidades não sejam consideradas enquanto irrelevantes. As diferenças de classe, gênero, sexualidade, origem, idade e condição física são frequentemente observadas pelas mulheres negras no seu fazer ativista".

O texto analisa com densidade e nos mostra a potência analítica e política dos estudos desenvolvidos por mulheres negras no âmbito das pós-graduações, isto pelo deslocamento crítico que operam desde às margens (hooks 2015), experiência de onde emerge o conceito de encruzilhada.

Ainda no campo das ações afirmativas, mas no contexto da educação básica, no interior do estado do Rio Grande do Sul, o texto da autoria de Cristiane Barbosa Soares e Alinne de Lima
Bonetti, "Marcadores sociais da diferença na experiência escolar de jovens estudantes negras", apresenta os resultados de pesquisa etnográfica realizada em uma escola de periferia, na cidade de Uruguaiana, em 2017, principalmente a partir da interlocução com jovens negras na faixa etária entre 12 a 15 anos de idade. Da pesquisa de campo realizada, emergiram três categorias a partir das quais conduziram a análise: identidade, representação e resistência. Para tanto, lançaram mão, principalmente, da abordagem de Avtar Brah (2006) sobre os marcadores de diferença em contextos relacionais. Embora com perspectiva analítica distinta em relação ao primeiro texto deste dossiê, sobre pesquisadoras negras nas pós-graduações, também destacou o "nós" que emerge dos processos de resistências de mulheres negras. As autoras destacaram a relação intergeracional, especialmente as estabelecidas entre as mulheres da familia, no sentido de um enfrentamento ao racismo no contexto escolar.

Os dois textos seguintes desenvolvem o tema das políticas públicas no campo de gênero, saúde e direitos. O texto "La dimensión global de las políticas públicas de género y salud en América Latina: un análisis decolonial", da autoria de Laura Cecilia López, Luanda Rejane Soares Sito e Yadira Eugenia Borrero-Ramírez, apresenta uma análise crítica de documentos produzidos por atores globais com o fim de orientar políticas de gênero em contextos latino-americanos. A análise de discurso de documentos produzidos pela Comisión Económica para América Latina y el Caribe (Cepal) e pela Organización Panamericana de Salud (OPS), especialmente considerando o período 2015-2020, foi realizada desde uma abordagem decolonial (Lugones 2008; Viveiros Vigoya 2018) e orientada por uma perspectiva crítica do conceito de gênero a partir do Sul Global (Mohanty 2008; Connell 2016). As autoras demonstraram este processo de duplo fazer do estado e do gênero (Vianna e Lowenkron 2017), a partir de conceitos, indicadores e instrumentos produzidos desde racionalidades neoliberais e que acabam por reproduzir as desigualdades de gênero. Segundo elas, "el neoliberalismo se 
presenta como 'neutro' en términos de género, promoviendo al individuo (sin género) como 'actor racional' y 'emprendedor'. Sin embargo, éste funciona como una forma de politica masculinista debido al poderoso papel que desempeña el estado en el orden de género".

Nesta mesma linha que analisa a produção simultânea do gênero e do estado, mas desde um aparato conceitual distinto, Tatiana Vargas Maia, no texto "Can the criminalization of reproductive rights be a nationalist project? An analysis of the 5069/2013 bill in the Brazilian National Congress", analisa um projeto de lei federal em tramitação no Congresso Federal - o PL 5069/2013 - no âmbito dos direitos reprodutivos, demonstrando o modo de intersecção entre gênero, raça e nação.

Na sequência, dois textos que enfocam dimensões do cuidado, em perspectiva de gênero. $O$ texto de Diana Manrique García, intitulado "Estéticas de (re) existência: aproximaciones rituales como parte de las rutas del cuidado en la amazonia boliviana", nos propicia seguir outras linhas de resistência, a partir da dança, com centralidade no corpo das mulheres, na Amazônia boliviana. O texto "Trabalho e familia de trabalhadoras domésticas em tempos de pandemia: uma análise interseccional", de Marta Maria Valeriano e Tania Ludmila Dias Tosta, este último sendo o único a enfocar o contexto da pandemia e o modo como intensificou desigualdades sociais.

Por fim, o dossiê encerra com três textos teóricos e que visam refletir sobre possiveis apropriações do conceito de interceccionalidades nas ciências sociais, um primeiro, alargando a noção de agência, no texto "Tecendo fios entre interseccionalidade, agência e capacidades na teoria sociológica", da autoria de Márcio Ferreira de Souza, Silvana Aparecida Mariano e Lina Penati Ferreira. Na sequência, o texto "Um passo além? O que a abordagem interseccional pode oferecer aos estudos urbanos", de Eliane Alves da Silva, que alarga as possibilidades do contexto na sociologia urbana e, encerrando o dossiê, uma abordagem da ciência política, desenvolvida por Bruna Cristina Jaquetto Pereira.
O conjunto dos textos, mais do que apresentarem uma genealogia do conceito de interseccionalidades, oferecem distintas abordagens que ampliam o horizonte das ciências sociais, como produzem potentes críticas epistemológicas, se apresentando como um campo aberto de resistências às narrativas e práticas hegemônicas ocidentais.

\section{Referências}

Brah, Avtar. 2006. Diferença, diversidade, diferenciação. Cadernos Pagu 26: 329-376. https://doi.org/10.1590/ S0104-83332006000100014.

Connell, Raewyn. 2016. Gênero em termos reais. São Paulo: nVersos.

hooks, bell. 2015. Mulheres negras: moldando a teoria feminista. Revista Brasileira de Ciência Política 16: 193210. https://doi.org/10.1590/0103-335220151608.

Lugones, María. 2008. Colonialidad y género. Tabula Rasa 9: 73-101. https://doi.org/10.25058/20112742.340.

Mohanty, Chandra. 2008. Bajo los ojos de Occidente. Academia feminista y discursos coloniales. In Descolonizando el feminismo: teorias y prácticas desde los márgenes, organizado por Liliana Suárez Navaz y Aida Hernández, 117-163. Madrid: Cátedra.

Vianna, Adriana e Laura Lowenkron. 2017. O duplo fazer do gênero e do Estado: interconexões, materialidades e linguagens. Cadernos Pagu, 51: e175101. https://doi. org/10.15.90/18094449201700510001.

Viveros Vigoya, Mara. 2018. As cores da masculinidade. Experiências interseccionais e práticas de poder na nossa América. Rio de Janeiro: Papeis Selvagens.

\section{Miriam Steffen Vieira}

Doutora em Antropologia pela Universidade Federal do Rio Grande do Sul (Ufrgs), em Porto Alegre, RS, Brasil; docente da Universidade do Vale do Rio dos Sinos (Unisinos), em São Leopoldo, RS, Brasil e da Universidade de Cabo Verde (Uni-CV), em Praia, Itha de Santiago, Arquipélago de Cabo Verde.

\section{Eufémia Vicente Rocha}

Doutora em Ciências Sociais pela Universidade de Cabo Verde (Uni-CV), em Praia, Ilha de Santiago, Arquipélago de Cabo Verde e docente na mesma instituição.

Os textos deste artigo foram revisados pela Poá Comunicação e submetidos para validação da autora antes da publicação. 